\title{
Role of phenolics from Spondias pinnata bark in amelioration of iron overload induced hepatic damage in Swiss albino mice
}

\author{
Dipankar Chaudhuri ${ }^{\dagger}$, Nikhil Baban Ghate ${ }^{\dagger}$, Sourav Panja and Nripendranath Mandal ${ }^{*}$
}

\begin{abstract}
Background: Crude Spondias pinnata bark extract was previously assessed for its antioxidant, anticancer and iron chelating potentials. The isolated compounds gallic acid (GA) and methyl gallate (MG) were evaluated for their curative potential against iron overload-induced liver fibrosis and hepatocellular damage.

Methods: In vitro iron chelation property and in vivo ameliorating potential from iron overload induced liver toxicity of GA and MG was assessed by different biochemical assays and histopathological studies.

Results: MG and GA demonstrated excellent reducing power activities but iron chelation potential of MG is better than GA. Oral MG treatment in mice displayed excellent efficacy (better than GA) to significantly restore the levels of liver antioxidants, serum markers and cellular reactive oxygen species in a dose-dependent fashion. Apart from these, MG exceptionally prevented lipid peroxidation and protein oxidation whereas GA demonstrated better activity to reduce collagen content, thereby strengthening its position as an efficient drug against hepatic damage/fibrosis, which was further supported by histopathological studies. Alongside, MG efficiently eliminated the cause of liver damage, i.e., excess iron, by chelating free iron and reducing the ferritin-bound iron.
\end{abstract}

Conclusions: The present study confirmed the curative effect of GA and MG against iron overload hepatic damage via their potent antioxidant and iron-chelating potential.

Keywords: Hemosiderosis, Oxidative stress, Antioxidant enzymes, Lipid peroxidation, Liver fibrosis

\section{Background}

An imbalance in pro-oxidant/antioxidant homeostasis eventually gives rise to the physical condition known as "oxidative stress". An irregular surge in oxidants such as reactive species of oxygen (ROS) and nitrogen (RNS) is generated endogenously through mitochondrial respiration as well as through exogenous oxidizing agents including ionizing radiation, heavy metals, and hypoxia. These oxidants come in contact with different biological molecules such as proteins, lipids and DNA, thereby disrupting them and causing maladies such as cancer, atherosclerosis, cardiovascular disease, liver injury, aging and inflammatory

\footnotetext{
* Correspondence: mandaln@rediffmail.com

${ }^{\dagger}$ Equal contributors

Division of Molecular Medicine, Bose Institute, P 1/12, C. I. T. Road, Scheme VIIM, Kolkata 700054, West Bengal, India
}

diseases [1]. Previous research has indicated that redoxactive metals such as iron also play a major role in ROS over production, mainly through highly reactive hydroxyl radicals by undergoing redox cycling [2]. Conversely, liver executes the normal metabolic balance of the body as well as biotransformation, detoxification and excretion of several toxic by-products. Increasing evidence has indicated that oxidative stress and its associated damage designate a common association between different forms of chronic liver injuries and hepatic fibrosis [3] due to iron overload [4]. Thus, any substance that is capable of providing protection against metal toxicity by trapping free radicals or by chelating metal ions that would consequently terminate the chain reaction of free radicals acts as an antioxidant [5]. In addition to endogenous antioxidant systems, frequent consumption of food that is rich in 
natural antioxidants also exhibits increased resistance to oxidative stress by altering the redox environment and is associated with a lower risk of many oxidative stress-related diseases.

Several phenolics and flavonoids from natural resources effectively scavenge different free radicals through their relevant iron chelating capabilities. Previous reports suggested that these types of compounds could also be used to treat iron-induced liver toxicity [6]. Crude Spondias pinnata (Linn. f.) Kurz (Fam. Anacardiaceae) extract was previously studied for its in vitro and in vivo antioxidant and iron chelating potential, which also demonstrated the presence of significant amounts of phenolic and flavonoid compounds $[7,8]$. These previous studies prompted us to isolate phenolic compounds from Spondias pinnata bark and evaluate their ameliorating effect on iron overload-induced hepatotoxicity and hepatic fibrosis in mice.

\section{Methods \\ Reagents}

Bathophenanthroline sulfonate disodium salt, 5,5'-dithiobis-2-nitrobenzoic acid (DTNB) and N-(1-Naphthyl) ethylenediamine dihydrochloride (NED) were procured from Sisco Research Laboratories Pvt. Ltd, India. 1-chloro-2,4dinitrobenzene (CDNB), Dimethyl-4-aminobenzaldehyde, and $\mathrm{N}, \mathrm{N}$ - dimethyl-4-nitrosoaniline ammonium iron (II) sulfate hexahydrate $\left(\left(\mathrm{NH}_{4}\right)_{2} \mathrm{Fe}\left(\mathrm{SO}_{4}\right)_{2}, 6 \mathrm{H}_{2} \mathrm{O}\right)$ were obtained from Merck, Mumbai, India. Guanidine hydrochloride and Iron-dextran was purchased from Sigma-Aldrich, USA. Cipla Ltd., India provided Desirox (Generic name-Deferasirox). All of the other used reagents were of molecular biology grade and were obtained from reputable suppliers.

\section{Test animals}

In vivo experiments were performed abiding by the guidelines of the Committee for the Purpose of Control and Supervision of Experiments on Animals (CPCSEA), Ministry of Environment and Forest, Govt. of India with due approval from the Institutional Animal Ethics Committee, Bose Institute (Registration. No. 95/1999/CPCSEA). Male Swiss albino mice $(20 \pm 2 \mathrm{~g})$ were obtained from the Chittaranjan National Cancer Institute (CNCI), Kolkata, India and were acclimated under a constant $12 \mathrm{~h}$ light/ dark cycle at $22 \pm 2{ }^{\circ} \mathrm{C}$. The animals were fed on general laboratory diet and water ad libitum. Experimental animals were taken care every $6 \mathrm{~h}$ during the treatment period and it was observed that there was no unwanted animal death. All surgeries were done using ethyl ether as anesthetic (by inhalation in a ethyl ether saturated chamber inside a fume hood), taking utmost care to reduce suffering.

\section{Plant material}

S. pinnata bark was collected from the villages of Bankura district, West Bengal, India and the plant was authenticated by Dr. Jayaram Hazra, Director, Central Research Institute of Ayurveda (CRIA), Kolkata, India. The herbarium was submitted at CRIA, Kolkata with an accession no of CRHS 111/08.

\section{Extraction and isolation of phyto-compounds}

Different compounds were isolated following the method of Chaudhuri, et al. [9]. Briefly, the S. pinnata stem bark was cut into small pieces, dried, ground into powder, and extracted with $70 \%$ methanol and water. The lyophilized extract was re-extracted successively with hexane, chloroform, ethyl acetate and water. All of the fractions were concentrated in reduced pressure, and the ethyl acetate fraction was further purified through silica gel column chromatography. Dichloromethane and methanol elution yielded four compounds namely SPE1, SPE2, SPE3 and SPE4. Structures of the bioactive compounds were analysed using different spectroscopic methods such as EIMS (JEOL JMS-700, Germany), FT-IR spectra recorded in $\mathrm{KBr}$ (Perkin Elmer, USA) and different nuclear magnetic resonance (NMR) experiments including ${ }^{1} \mathrm{H}$ and ${ }^{13} \mathrm{C}$ with a Bruker-500 MHz NMR Spectrometer (Germany).

\section{In vitro reducing power and iron chelation potential of the isolated compounds}

$\mathrm{Fe}^{3+}$-reducing power of the compounds was determined by a standard method [10] where ascorbic acid was used as standard. Various concentrations $(0-1.0 \mathrm{mg} / \mathrm{ml})$ of the compounds were tested and their absorbance was measured at $700 \mathrm{~nm}$ against an appropriate blank. The $\mathrm{Fe}^{2+}$ chelating ability was determined as described earlier, and the result was expressed as inhibition percentage [7]. Briefly, in HEPES buffer $(20 \mathrm{~m} \mathrm{~mol} / \mathrm{l}, \mathrm{pH}$ 7.2) medium, test samples $(0-120 \mu \mathrm{g} / \mathrm{ml})$ and positive control EDTA $(0-20 \mu \mathrm{g} / \mathrm{ml})$ were separately added to a $12.5 \mu \mathrm{mol} / \mathrm{l}$ ferrous sulfate solution and $75 \mu \mathrm{mol} / \mathrm{l}$ ferrozine was added to start the reaction. After rapid vortexing the mixture was left at room temperature for $20 \mathrm{~min}$ and absorbance was taken at $562 \mathrm{~nm}(\mathrm{OD})$. The percentage of inhibition of ferrozine- $\mathrm{Fe}^{2+}$ complex formation was determined by the formula- \% of inhibition $=[($ Control OD-Sample OD $) /$ Control OD] $\times 100$. All tests were performed six times.

\section{In vivo hepato-ameliorating activity}

\section{Experimental design and tissue preparation}

In total, nine groups of mice were randomly prepared consisting of six mice per group. Among them, one group received normal saline only, which was labeled as a blank (B); however, other groups were intoxicated with five doses of $100 \mathrm{mg} / \mathrm{kg}$ b.w. iron-dextran (one dose 
every alternative days) by intraperitoneal injection (ip). Of the groups, one iron-dextran group (C) was treated orally with only saline, and other groups were treated orally with $2 \mathrm{mg} / \mathrm{kg}$ b.w. gallic acid (GA) (R2), $2 \mathrm{mg} / \mathrm{kg}$ b.w. methyl gallate (MG) (S2), $4 \mathrm{mg} / \mathrm{kg}$ b.w. GA (R4), $4 \mathrm{mg} / \mathrm{kg}$ b.w. MG (S4), $8 \mathrm{mg} / \mathrm{kg}$ b.w. GA (R8), $8 \mathrm{mg} / \mathrm{kg}$ b.w. MG (S8) test samples and $20 \mathrm{mg} / \mathrm{kg}$ b.w. desirox (D) for 21 consecutive days starting the day following the first iron-dextran injection. All experimental animals were sacrificed on $22^{\text {nd }}$ day under mild anesthesia (ethyl ether), and cardiac puncture was performed to collect blood and serum was separated and stored at $-80{ }^{\circ} \mathrm{C}$. After collecting the blood, the liver was quickly excised, cleaned thoroughly with cold phosphate buffer saline (PBS) to remove the remaining blood and cut into three sections. The major liver portion was dissected and homogenized using 10 volumes of $0.1 \mathrm{M}$ phosphate buffer (pH 7.4) supplemented with $0.15 \mathrm{M} \mathrm{NaCl}$ and $5 \mathrm{mM}$ EDTA and centrifuged for $30 \mathrm{~min}$ at $8000 \mathrm{~g}$ in the cold. The clear homogenate (supernatant) was collected and the protein concentration was quantified by Folin-Lowry method [11], where BSA was used as a standard; the remaining supernatant was then stored at $-80{ }^{\circ} \mathrm{C}$. Second liver fragment was treated with a mixture of nitric acid and sulfuric acid (1:1) to analyze the iron content. The last portion was processed for histopathological examinations.

\section{Serum ferritin and liver iron levels}

Manufacturer's instructions were followed to quantify serum ferritin levels using an ELISA kit from Monobind Inc., USA. Liver iron content was quantified using a previously reported method [12]. Briefly, samples were mixed with bathophenanthroline sulfonate and incubated at $37^{\circ} \mathrm{C}$ for $30 \mathrm{~min}$, and absorbance was recorded using a spectrophotometer (Shimadzu, UV-2401PC, Japan) at $535 \mathrm{~nm}$.

\section{In vitro ferritin iron release}

Iron reduction and release were determined using ferrozine, a spectrophotometric reagent for iron, as previously described [13]. Briefly, the reaction was initiated by adding different concentrations $(100-500 \mu \mathrm{g} / \mathrm{ml})$ of test compounds in $50 \mathrm{mM}$ phosphate buffer ( $\mathrm{pH} 7.0$ ) containing $200 \mu \mathrm{g}$ ferritin and $500 \mu \mathrm{M}$ ferrozine, and the absorbance change was measured for $20 \mathrm{~min}$ at $560 \mathrm{~nm}$. The reaction mixture excluding the test samples was used as a reference.

\section{Serum markers}

Aspartate amino transferase (ASAT), alanine amino transferase (ALAT), and bilirubin levels in serum were evaluated using commonly available kits from Merck, India. Similarly, alkaline phosphatase (ALP) levels were measured by a kit from Sentinel diagnostics, Italy.

\section{Antioxidant enzymes}

Superoxide dismutase (SOD), catalase (CAT), glutathioneS-transferase (GST), and reduced glutathione (GSH) levels were measured using previously described methods [14-17].

\section{Measurement of ROS levels in liver, spleen homogenate and serum}

ROS levels in liver and spleen tissue homogenate and serum were estimated using 2,7-dichlorofluorescein diacetate (DCFDA) following the method of Rashid et al. [18] with slight modifications. Briefly, the sample containing $50 \mu \mathrm{g}$ protein was mixed with $1 \mathrm{ml}$ assay buffer $(130 \mathrm{mM} \mathrm{KCL}, 5 \mathrm{mM} \mathrm{MgCl}, 20 \mathrm{mM}$ $\mathrm{NaH}_{2} \mathrm{PO}_{4}, 20 \mathrm{mM}$ Tris $\mathrm{HCl}, 30 \mathrm{mM}$ Glucose and $10 \mu \mathrm{M}$ DCFDA) and incubated at $37{ }^{\circ} \mathrm{C}$ for $15 \mathrm{~min}$ in the dark. DCF formation was recorded at the excitation wavelength of $488 \mathrm{~nm}$ and emission wavelength of $523 \mathrm{~nm}$ for $2 \mathrm{~min}$ using a fluorescence spectrometer (Hitachi, Model F4500) that had been equipped with a FITC filter.

\section{Evaluation of liver damage and fibrosis}

Thiobarbituric acid reactive substances (TBARS) quantities were measured to evaluate the levels of lipid peroxidation [19]. Protein oxidation levels were resolved by estimating protein carbonyl contents [20]. Collagen content, an important marker of liver fibrosis, was evaluated using previously described methods [21]. Collagen content in each sample was determined by multiplying 7.69 by overall hydroxyproline content [22].

\section{Histopathological studies}

Excised liver samples were cleaned with saline and fixed for two days in $10 \%$ buffered neutral formalin. Sections $(5 \mu \mathrm{m}$ thick) were paraffin-embedded and stained with hematoxylin and eosin (morphological examination), Perls' Prussian blue dye (iron content) and Masson's trichrome stain (liver fibrosis). Stained sections were checked microscopically for histopathological changes.

\section{Statistical analysis}

All of the data were reported as the mean \pm SD of six measurements. Statistical analysis was performed using KyPlot version 2.0 beta 15 (32 bit) and Microsoft excel 2010. The relationships between the groups were evaluated using a paired $t$-test for in vitro study and one way ANOVA followed by Tukey's post hoc tests for in vivo study, and a $p$ value of $<0.05$ was considered to be statistically significant. 


\section{Results}

In vitro iron chelation and reducing power potential

The iron chelation potential of the isolated compounds was measured using two essential methods: $\mathrm{Fe}^{3+}$ reducing power and iron chelation properties. SPE1 and SPE2 failed to show any activity in both the assays and SPE3, standard ascorbic acid demonstrated corresponding reducing power activities, which were although higher than SPE4 (Fig. 1a). Conversely, SPE4 demonstrated excellent and better in vitro iron chelation activity than SPE3 (Fig. 1b). The structure of SPE3, SPE4 (Fig. 2) was determined as Gallic acid (GA), and Methly gallate (MG) using different spectroscopic experimental data shown in Additional file 1. The $\mathrm{IC}_{50}$ value of MG and GA in iron chelation property is
$129.85 \pm 6.90 \mu \mathrm{g} / \mathrm{ml}$ and $1007.35 \pm 141.31 \mu \mathrm{g} / \mathrm{ml}(n=6)$ respectively.

\section{In vivo studies}

Serum ferritin and liver iron levels

Increase in hepatic iron content and serum ferritin levels were observed in the iron-overloaded mice compared with the normal mouse group. Upon GA and MG administration, notable tendencies of a dose-dependent reduction in liver iron content (Fig. 3a) as well as serum ferritin concentrations (Fig. 3b) were observed. The highest dose of MG demonstrated better activity than the standard drug desirox and significantly eliminated the excess iron, thus making the condition equal to the normal mice group.
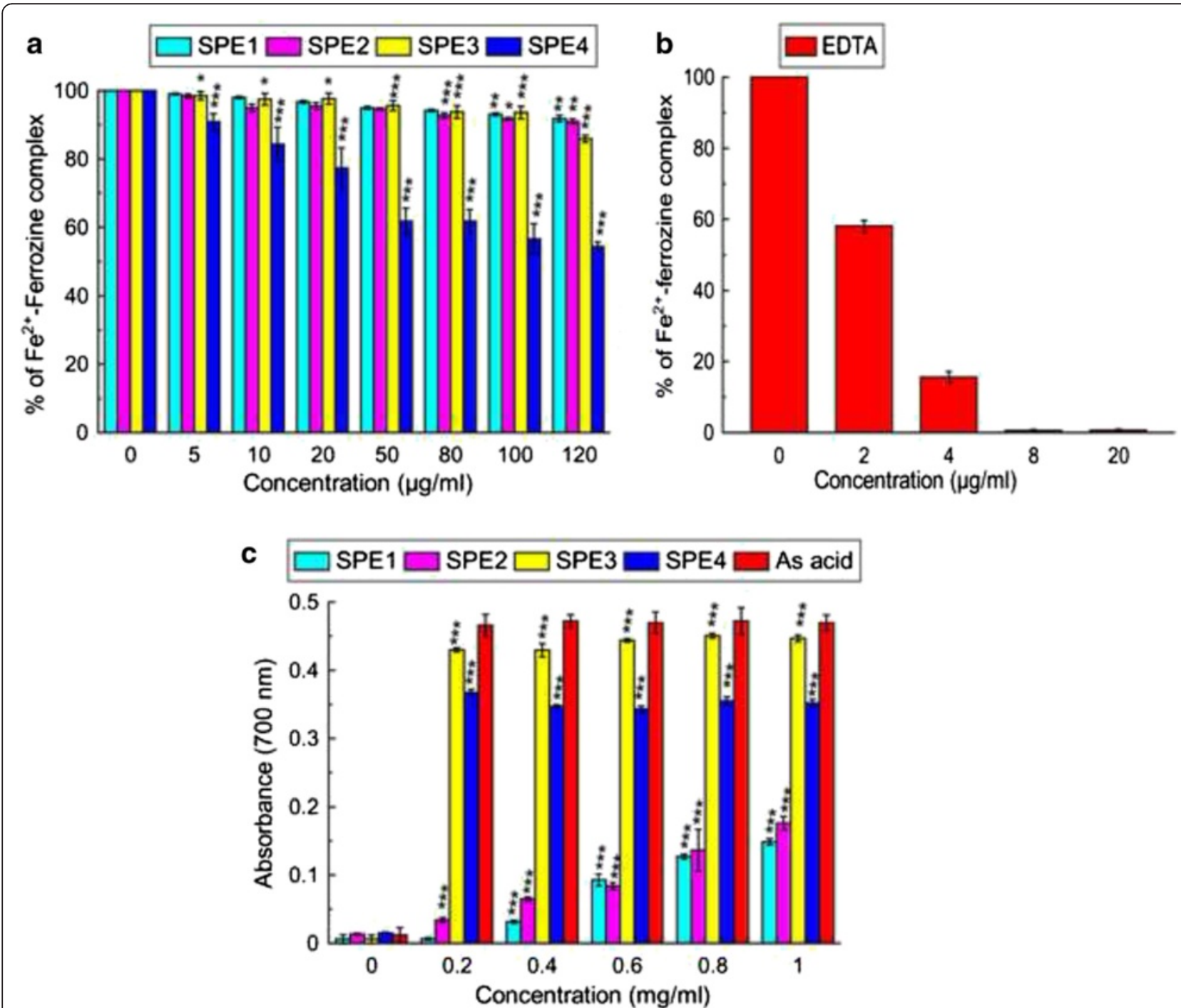

Fig. 1 Iron chelation and reducing power activity of the isolated compounds. a iron chelation activity of the compounds, b Standard EDTA c Reducing power assay. 'As acid' represents Ascorbic Acid. The results represent the mean \pm S.D. $(n=6)$. ${ }^{*} p<0.05,{ }^{* *} p \leq 0.01$ and ${ }^{* * *} p<0.001$ vs. control 
<smiles>COC(=O)c1cc(O)c(O)c(O)c1</smiles>

Fig. 2 Chemical structure of the identified compounds. a Gallic acid and $\mathbf{b}$ Methyl gallate from S. pinnata bark

\section{Iron release from ferritin}

A dose dependent increase in the formation of the ferrous-ferrozine complex $\left[(\mathrm{Fe}(\text { ferrozine }) 3)^{2+}\right]$ was measured to quantify the efficiency of GA and MG in releasing the reduced iron from ferritin. Experiments without test samples formed insignificant quantities of the reduced iron ferrozine complex, whereas increasing concentrations significantly released iron from ferrozine with time (Fig. 4a). MG also demonstrated better activity than GA, but when the percentage of iron released from ferritin and the reducing power of the test samples were correlated (Fig. 4b).

\section{Antioxidant enzymes}

The iron-overloaded condition stimulated an oxidative stress condition that significantly reduces levels of antioxidant enzymes and non-enzymatic antioxidant GSH compared with normal mice. Oral administration of GA and MG indicated significant restoration of the antioxidant enzymes almost to the normal state. In the case of SOD (Fig. 5a), MG exhibited better activity than standard treatment. At the highest MG dose, catalase
(Fig. 5b), GST (Fig. 5c) and GSH (Fig. 5d) levels nearly approached standard desirox levels, while GA displayed moderate activity.

\section{ROS levels}

The ROS levels in liver and spleen homogenates as well as serum were increased in the iron overloaded mice compared with normal mice. Upon GA and MG administration, the levels gradually regressed towards the normal condition (Fig. 6a, b and c, respectively). Treatment with GA reduced the levels of ROS in liver and spleen homogenate better than MG as well as desirox treatment. But serum ROS levels were more greatly reduced by MG than GA treatment.

\section{Serum markers}

The elevated levels of serum enzymes and bilirubin markedly dose-dependently decreased after oral GA and MG administration. From Table 1, it is clear that higher doses of MG displayed better activity than GA and the standard desirox in all cases except for bilirubin.

\section{Biochemical parameters of liver damage}

The effect of iron overload on liver damage was measured by the level of lipid peroxidation, protein carbonyl and collagen content in the liver homogenate. When treated with the test compounds, thiobarbituric acid reactive substance (TBARS) levels, which measures MDA, were substantially decreased (Fig. 7a). In case of protein carbonyl content, MG exceptionally prevented protein oxidation because protein carbonyl content is almost similar to normal mice (Fig. 7b). However, in the case of hydroxylproline, i.e., collagen content, GA exhibited marginally better activity than MG and similar activity to standard desirox (Fig. 7c).
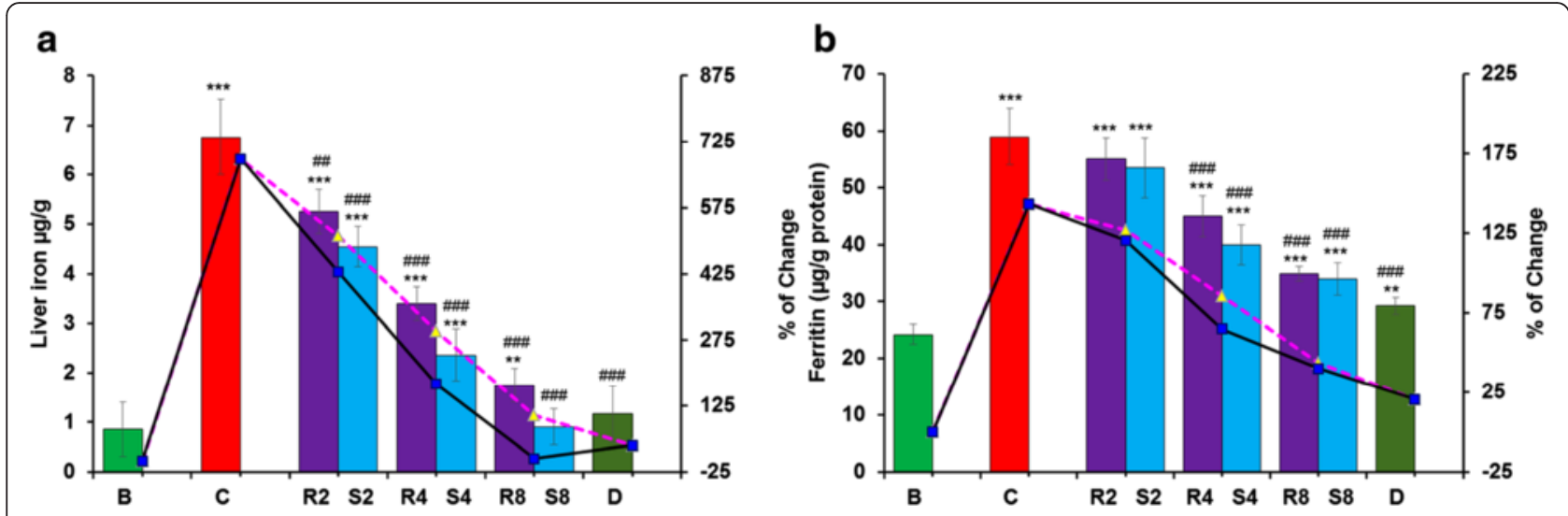

Fig. 3 Iron removal potential of GA and MG. a Hepatic iron content, b Serum ferritin content. Mouse groups (B; C; R2; S2; R4; S4; R8; S8; D) were treated as described in the 'Experimental design and tissue preparation' section. Values are expressed as the mean \pm SD of six mice. ${ }^{* *} p \leq 0.01$, ${ }^{* * *} p \leq 0.001$ compared with the blank and ${ }^{\# \# \#} p \leq 0.001$ compared with the control 

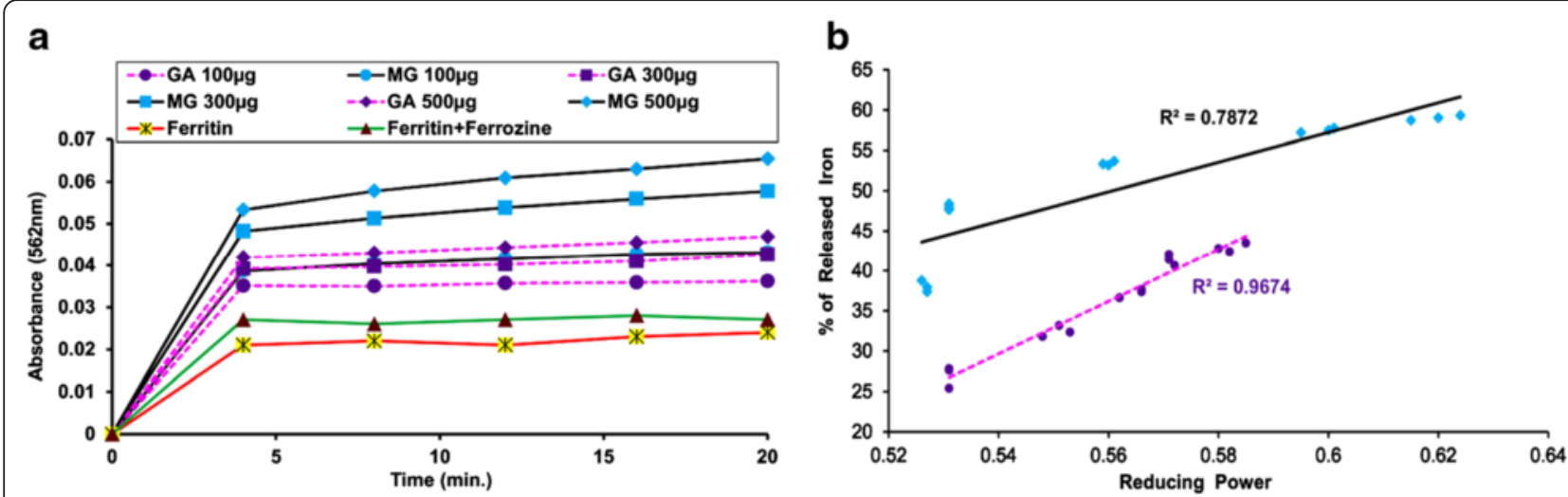

Fig. 4 Iron release from ferritin. a Iron release from ferritin $\mathbf{b}$ Correlation between iron released from ferritin with reducing power. Iron released in response to increasing amounts $(100-500 \mu \mathrm{g})$ of both GA and MG was plotted against reducing power displayed at the same doses

\section{Histopathological study}

Biopsy sections were stained with hematoxylin and eosin for morphologic evaluation, Perls' Prussian Blue stain for assessment of iron loading, and Masson's trichrome stain for assessment of fibrosis. Liver sections from normal mice demonstrated normal cell morphology with prominent nuclei in well-preserved cytoplasm and prominent central vein without cellular infiltration (Fig. 8a), whereas iron dextran overloaded mice demonstrated various degrees of pathological changes including ballooning degeneration, inflammation, loss of cellular boundaries, and hepatocellular necrosis (Fig. 8b). In contrast, the liver sections taken from GA (Fig. 8d-f) and MG (Fig. 8g-i) treated mice groups displayed attenuation of pathogenicity and gradual reversal to normal cyto-architecture with a higher dosage, thus restoring the normal condition. Figure $8 \mathrm{c}$ represents

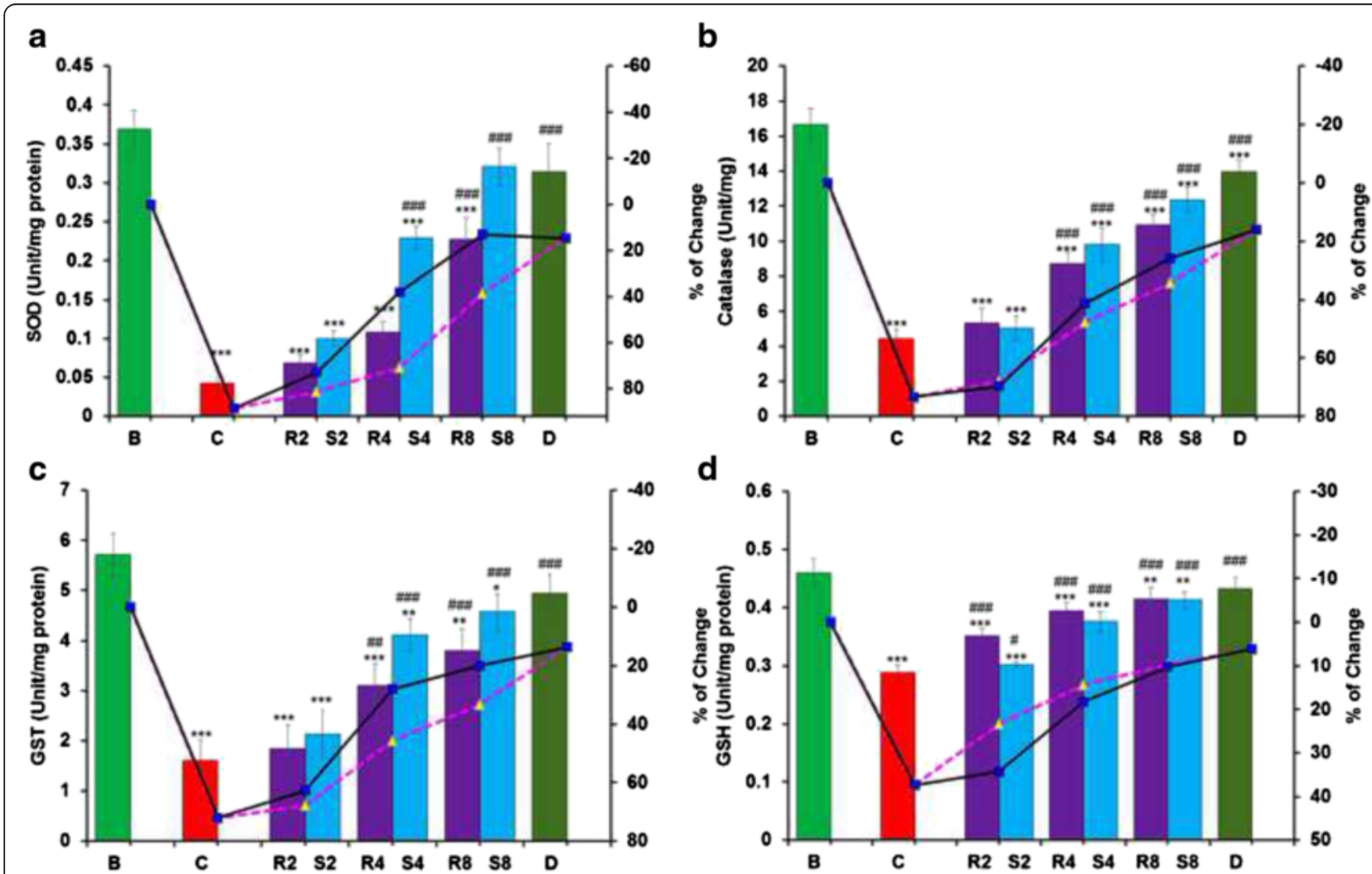

Fig. 5 Effect of GA and MG treatment on liver antioxidant enzyme levels. a SOD, b Catalase, c GST, d GSH. Mouse groups (B; C; R2; S2; R4; S4; R8; S8; D) were treated as described in the 'Experimental design and tissue preparation' section. Values are expressed as the mean \pm SD $(n=6)$. ${ }^{*} p<0.05,{ }^{* *} p \leq 0.01,{ }^{* *} p \leq 0.001$ compared with the blank and ${ }^{*} p \leq 0.05,{ }^{\# \#} p \leq 0.01,{ }^{\# \# \#} p \leq 0.001$ compared with the control 


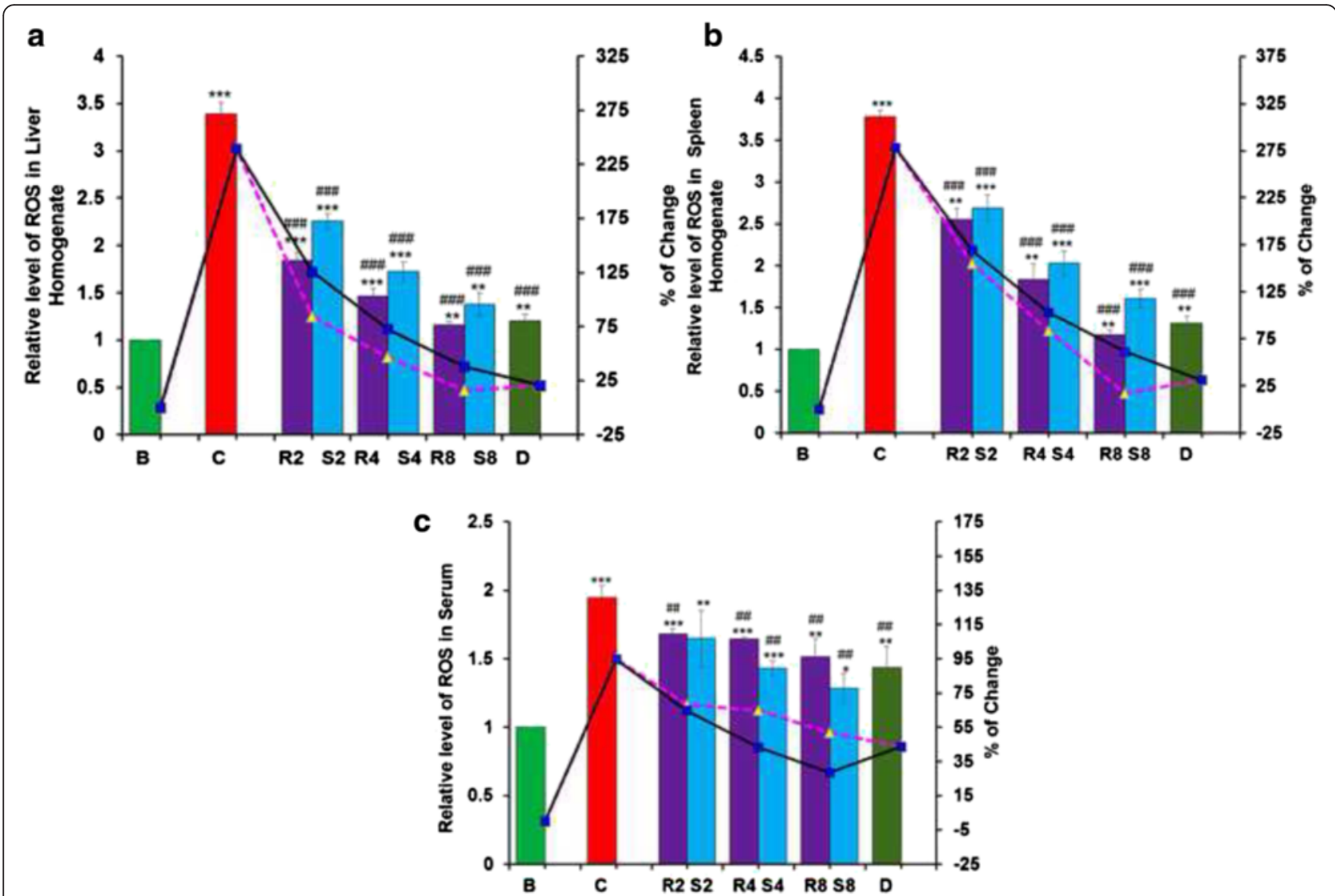

Fig. $\mathbf{6}$ Restoration of ROS levels in liver, spleen and serum after GA and MG treatment. a Relative ROS levels in liver homogenates, $\mathbf{b}$ Relative ROS levels in spleen homogenates $\mathbf{c}$. Relative ROS levels in serum. Mouse groups (B; C;R2; S2; R4; S4; R8; S8; $\mathbf{d}$ were treated as described in the 'Experimental design and tissue preparation' section. Values are expressed as the mean \pm SD $(n=6) .{ }^{*} p<0.05,{ }^{* *} p \leq 0.01,{ }^{* * *} p \leq 0.001$ compared with the blank and ${ }^{\# \#} p \leq 0.01, \# \# p \leq 0.001$ compared with the control

liver sections of the desirox-treated group with improved histology, which is similar to the highest doses of GA and MG. Another detrimental effect of excess iron in liver is deposition of iron in the form crystalline ferritine and amorphous hemosiderin. Iron released from denatured ferritin, ferric oxide (unused iron) as well as broken hemoglobin formed a complex to store the iron known as hemosiderin. The iron within the deposits of hemosiderin is poorly available to the body and tissue sections stained with Perls' Prussian blue is commonly used to detect its deposition in liver tissue as blue patches. The liver sections from untreated iron overloaded mice demonstrated increased hemosiderin deposition (Fig. 9b) compared with normal mice (Fig. 9a). However, sections from the treated mice groups demonstrated a gradual decrease in hemosiderin deposition patches (Fig. 9d-f for GA and 9g-i for MG). The highest dose of MG exhibited a parallel effect to the standard desirox-treated group (Fig. 9c). Accumulated collagen in liver was also stained blue using Masson's trichrome. The microscopic observation suggested that the liver section of control mice revealed normal lobular architecture and distribution of collagen (Fig. 10a). From the liver section of iron-overloaded mice it is evident that the normal architecture of the liver is destroyed and the nodules surrounded by accumulated collagen indicating fibrous cirrhotic (Fig. 10b). However, after treatment with the test samples, a gradual decrease in the degree of collagen deposition was observed (Fig. 10d-f for GA and 10g-i for MG). Here, the highest MG dose also demonstrated a similar scenario compared with the standard desiroxtreated group (Fig. 10c).

\section{Discussion}

Free radicals and iron metal are essential entities of aerobic life and modulate various physiological functions [23]. In iron-overloaded liver, iron reacts with the cellular hydrogen peroxide to generate hydroxyl radical (Fenton reaction) which in turn initiate the propagation of various ROS. This situation leads to oxidative stress which damage in liver tissue mostly via lipid peroxidation of biological membranes [24]. However, the preventive system of our body is inadequate to handle excess free radicals; therefore, external antioxidant iron chelator supplements are essential to maintain healthy physiological conditions. An 
Table 1 The effect of GA and MG on serum marker enzymes (ALAT, ASAT and ALP) and Bilirubin in iron overloaded mice

\begin{tabular}{|c|c|c|c|c|c|c|c|c|}
\hline \multirow[t]{2}{*}{ Treatment } & \multicolumn{2}{|l|}{ ALAT (Unit/L) } & \multicolumn{2}{|l|}{ ASAT (Unit/L) } & \multicolumn{2}{|l|}{ ALP (Unit/L) } & \multicolumn{2}{|l|}{ Bilirubin (mg/dl) } \\
\hline & GA & MG & GA & MG & GA & MG & GA & MG \\
\hline B & $14.42 \pm 1.91$ & $14.42 \pm 1.91$ & $62.46 \pm 6.32$ & $62.46 \pm 6.32$ & $84.62 \pm 3.48$ & $84.62 \pm 3.48$ & $1.58 \pm 0.10$ & $1.58 \pm 0.10$ \\
\hline C & $64.60 \pm 4.32^{\times 3}$ & $64.60 \pm 4.32^{\times 3}$ & $234.91 \pm 8.30 \times 3$ & $234.91 \pm 8.30^{\times 3}$ & $252.63 \pm 4.92^{\times 3}$ & $252.63 \pm 4.92^{\times 3}$ & $3.15 \pm 0.18^{\times 3}$ & $3.15 \pm 0.18^{\times 3}$ \\
\hline 2 mg/kg b.w & $42.96 \pm 1.16^{\times 3 \times 3}$ & $36.93 \pm 0.93^{\times 3 \times 3}$ & $145.45 \pm 5.89 \times 3 \curlyvee 3$ & $141.51 \pm 11.57^{\times 3 \times 3}$ & $181.90 \pm 4.95 \times 3 \curlyvee 3$ & $173.41 \pm 2.93 \times 3 \times 3$ & $2.88 \pm 0.39 \times 3$ & $3.04 \pm 0.25^{\times 3}$ \\
\hline 4 mg/kg b.w & $32.17 \pm 2.16^{\times 3 Y 3}$ & $29.09 \pm 0.59^{\times 3 \times 3}$ & $114.78 \pm 8.20 \times 3 \curlyvee 3$ & $110.28 \pm 6.55^{\times 3 \curlyvee 3}$ & $145.10 \pm 6.46^{\times 3 Y 3}$ & $132.32 \pm 3.56^{\times 3 \times 3}$ & $2.47 \pm 0.24^{\times 3 \times 3}$ & $2.11 \pm 0.16^{\mathrm{X} Y 3}$ \\
\hline 8 mg/kg b.w & $23.22 \pm 0.95^{\times 3 Y 3}$ & $20.25 \pm 0.90^{\times 2 Y 3}$ & $83.56 \pm 4.86^{\times 3 \curlyvee 3}$ & $77.93 \pm 13.48^{\times 1 Y 3}$ & $118.69 \pm 3.79 \times 3 \times 3$ & $103.34 \pm 5.88^{\times 3 \times 3}$ & $2.10 \pm 0.12^{\times 3 \times 3}$ & $1.94 \pm 0.13^{\times 3 Y 3}$ \\
\hline D & $19.85 \pm 0.79 \times 3 Y 3$ & $19.85 \pm 0.79^{\times 3 \times 3}$ & $88.06 \pm 10.37^{\times 3 \times 3}$ & $88.06 \pm 10.37^{\times 3 \curlyvee 3}$ & $114.97 \pm 6.13^{\times 3 \curlyvee 3}$ & $114.97 \pm 6.13^{\times 3 \times 3}$ & $1.72 \pm 0.14^{Y_{3}}$ & $1.72 \pm 0.14^{Y_{3}}$ \\
\hline
\end{tabular}

Values are mean \pm SD of six observations. Treatment groups are B: Normal mice; C: Iron-dextran treated mice receiving normal saline; $2 \mathrm{mg} / \mathrm{kg}$ b.w. treated group; $4 \mathrm{mg} / \mathrm{kg}$ b.w. treated group; $8 \mathrm{mg} / \mathrm{kg}$ b.w. treated group; D: $20 \mathrm{mg} / \mathrm{kg}$ b.w. desirox treated group. X1: $p<0.05, X 2: p<0.01$ and X3: $p<0.001$ significant difference from normal mice (B) group. Y1: $p<0.05, \mathrm{Y} 2: p<0.01$ and Y3: $p<0.001$ significant difference from iron overloaded (C) group 


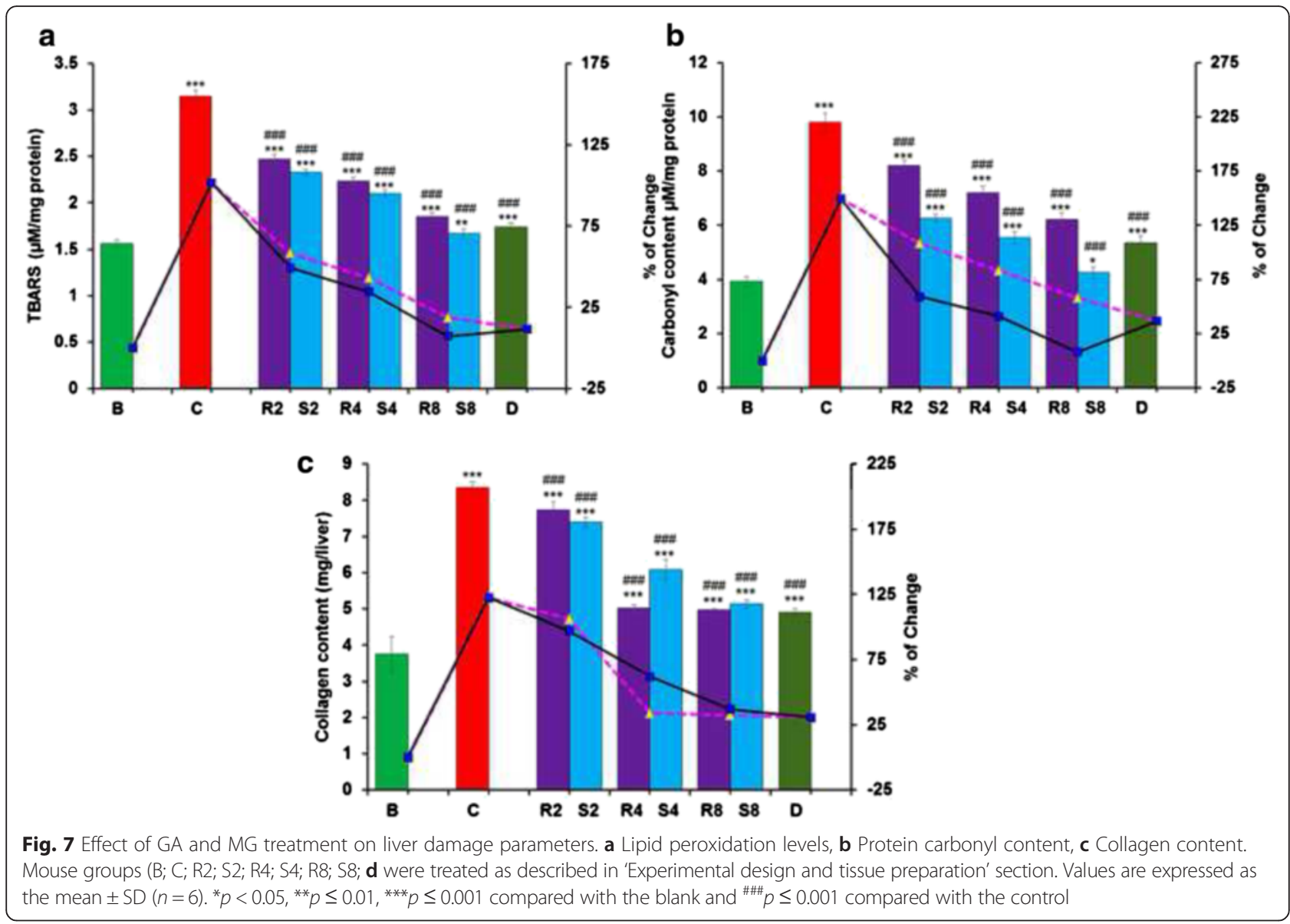

effective remedial strategy should act in a dual character by decreasing the oxidation rate; one method is sequestering and chelating the stored iron in cells [25], and the other is a radical trap (i.e., antioxidant activity). Though the development of some synthetic antioxidants and iron chelating drugs has thrived recently, they are not yet widely accepted as therapeutic agents due to several side effects and disadvantages. Thus, there is a growing demand to develop more effective and safe therapeutic approaches to chelate catalytically active cytosolic iron [25] and concurrently protect cells from excess free radicals. Several bio resources have already been reported as natural antioxidants with iron chelating potentials [26, 27].

Results of in vitro iron chelation and reducing power property of the isolated compound from ethyl acetate fraction suggest that on SPE3 and SPE4 do possessed both the activities where other two compounds failed to show any activity. So, the structure of SPE3 and SPE4 was elucidated and found to be gallic acid (GA) and methyl gallate (MG). MG exhibited better iron chelation than GA although their basic structure is alike. So, this iron chelation result further supported the findings of Yang et al. [28] who suggested that Fe(III) in Hepes buffer, pH 7.4 interacted with three molecules of MG and produced a $\mathrm{Fe}(\mathrm{III})-\mathrm{MG}_{3}$ complex with a stable octahedral geometry (binding constant- $\mathrm{K}$ is in the range of $1 \times 10^{34} / \mathrm{M}$ to $1 \times 10^{36} / \mathrm{M}$ ) and chelate-free iron better than GA.

Both the compounds, GA and MG have demonstrated excellent in vitro iron chelation anf reducing power potency, a study on the in vivo ameliorating effect of GA and MG in iron overloaded liver toxicity and liver fibrosis in mice was constructed. Hemochromatosis was created by intraperitoneal injection of iron-dextran. This process will not hamper intestinal iron absorption by the test compounds, which ultimately leads to iron overload in liver and serum [29].

The excess iron stored in the liver as ferritin or hemosiderin [30]. Thus, most procedures seek to measure liver iron levels for diagnosis of iron overload disease. In contrast, ferritin, a ubiquitous intracellular iron-binding protein, generally stores iron in a non-toxic ferric form and releases it in a controlled fashion whenever needed [31]. Serum ferritin is a key marker that was developed as a consequence of iron overload-induced hepatic toxicity, as blood ferritin content indirectly reveals the amount of hepatic iron content. The decrease in hepatic 

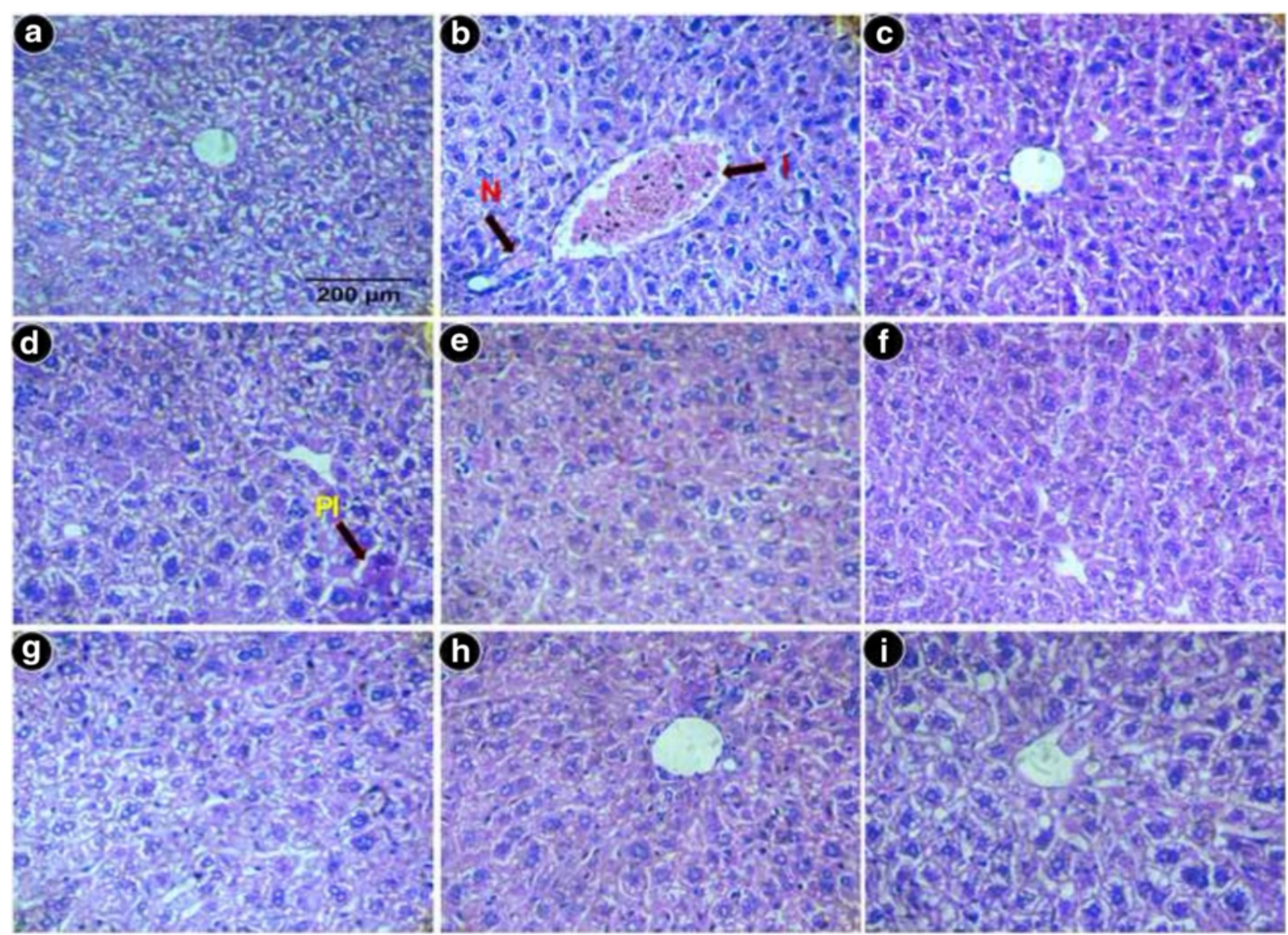

Fig. 8 Microscopic observation of mouse liver sections that had been stained with hematoxylin and eosin at $\times 400$. Liver sections from control mice with normal cytoarchitecture. b Iron-overloaded (iron dextran, $100 \mathrm{mg} / \mathrm{kg}$ b.w.) liver section demonstrates degeneration of cellular boundaries, fatty ballooning deterioration, inflammation (I), and necrosis (N). c Desirox-treated liver sections demonstrate reduced necrotic area. $\mathbf{d}$ Liver section from the R2 mouse group improved histology with portal inflammation (PI). e Liver section from the R4 mouse group (f) Liver section from the R8 mouse group $(\mathbf{g})$. Liver section from the S2 mouse group (h). Liver section from the S4 mouse group (i). Liver section from the S8 mouse group demonstrates improved histology with minimal necrotic area

iron deposition after MG treatment justified its in vitro iron-chelating effectiveness.

In hepatocytes, ferritin stores excess iron in the ferric state. To overcome iron overload, various readily available iron chelator drugs are administered, but many of them struggle with a narrow binding capacity for ferric iron $\left(\mathrm{Fe}^{3+}\right)$. Thus, reducing agents such as ascorbic acid need to be administered as supplements to upsurge the accessibility of stored iron to chelators [32]. From the result it was found that both MG and GA effectively release iron from ferritin which also nicely correlated with their reducing power capacity. GA possessed a greater correlation coefficient $\left(R^{2}=0.9674\right)$ than MG $\left(R^{2}=0.7872\right)$. This also validated the superior reducing power activity of GA over MG.

Living cells are equipped with an array of endogenous antioxidant enzymes such as GST, SOD, CAT and the small compound GSH, which are first line of defenses against excessive free radicals. Evaluating the levels of these antioxidant enzymes is a proper indirect way to assess pro-oxidant-antioxidant combat in tissues [33]. SOD destroys superoxide free radicals by converting them into $\mathrm{H}_{2} \mathrm{O}_{2}$, whereas catalase further decomposes excess $\mathrm{H}_{2} \mathrm{O}_{2}$ to $\mathrm{H}_{2} \mathrm{O}$ and $\mathrm{O}_{2}$. Catalase efficiency is so commendable that it cannot be saturated by any concentration of $\mathrm{H}_{2} \mathrm{O}_{2}$ [34]. The cellular GSH system is probably the most important cellular defense mechanism, which not only acts as a ROS scavenger but also regulates the intracellular redox state [35]. The results suggested that MG restore the antioxidant enzymes much better than GA and the activity is almost equal to standard drug Desirox (20 mg/kg.b.w) but in lower concentration (8 mg/kg.b.w).

The previous phenomenon can also be further supported by the obtained ROS levels in liver spleen homogenates and serum in iron overloaded condition 


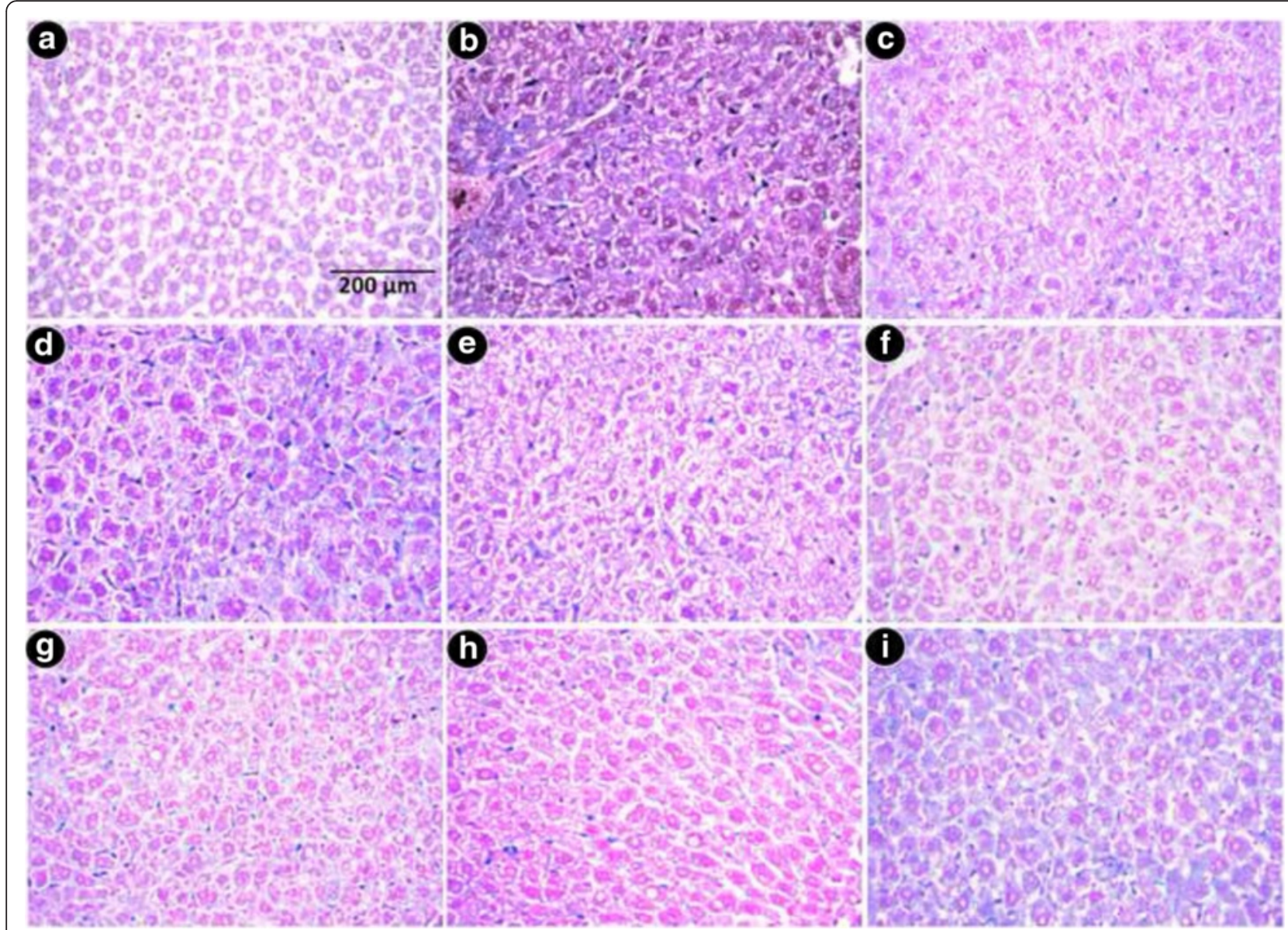

Fig. 9 Microscopic observation of liver sections stained with Perls' Prussian blue at $\times 400$. a Liver section from control mice demonstrates normal hemosiderin deposition patches (very low). $\mathbf{b}$ Liver sections from iron-overloaded mice display excess blue patches. $\mathbf{c}$ Desirox-treated liver section d Liver section from the R2 mouse group with lesser blue patches. e Liver section from the R4 mouse group (f). Liver section from the R8 mouse group (g). Liver section from the S2 mouse group (h). Liver section from the S4 mouse group (i). Liver section from the S8 mouse group. MG demonstrates improved histology, and a gradual reduction of blue patches indicates effective iron removal from the liver

as well as after treatment. Surprisingly, GA exhibited much better activity than MG and desirox, which also supported its excellent antioxidant and free radical scavenging potentials. On the other hand, MG exhibited better ROS level reduction in serum of the iron overloaded mice. It is speculated that MG, which is an excellent iron chelator, assists albumin to further chelate excess iron, thereby lowering serum ROS levels. Generally, albumin represents the predominant antioxidant in plasma, which is exposed to continuous oxidative stress [36]. Albumin concentrations increase in inflammation, and the antioxidant activities of albumin result from its ligand-binding capacities of ROS-producing metal such as copper and iron [37].

Levels of serum enzyme are checked in the clinical diagnosis to determine the condition of various diseases and tissue injury $[38,39]$. These enzymes are predominantly found in the hepatic cell and liver damage due to excess iron leads to the release of these intracellular enzymes into the blood [40] as evident by increased serum parameters (Table 1). The administration of the test compounds has reduced the increased level of the serum marker enzymes almost similar to the standard desirox. This result indicated towards their healing capabilities of hepatic parenchyma and regeneration of hepatocyte as well as its functional efficiency [41]. Hence, MG not only helped to overcome oxidative stress but also possessed better hepato-amelioration activity compared with GA.

Cell membrane lipid peroxidation is the most detrimental result of iron-induced oxidative stress mainly via hydroxyl radicals [42]. Lipid peroxidation (LPO) and the resulting end products such as malondialdehyde (MDA) act as an important factors of liver fibrosis by activating hepatic stellate cells, resulting in increased pro-collagen $\alpha_{1}$ (I) gene expression [43-45]. This relationship between lipid peroxidation and hepatic fibrosis is well established in a variety of liver diseases including hemochromatosis, 

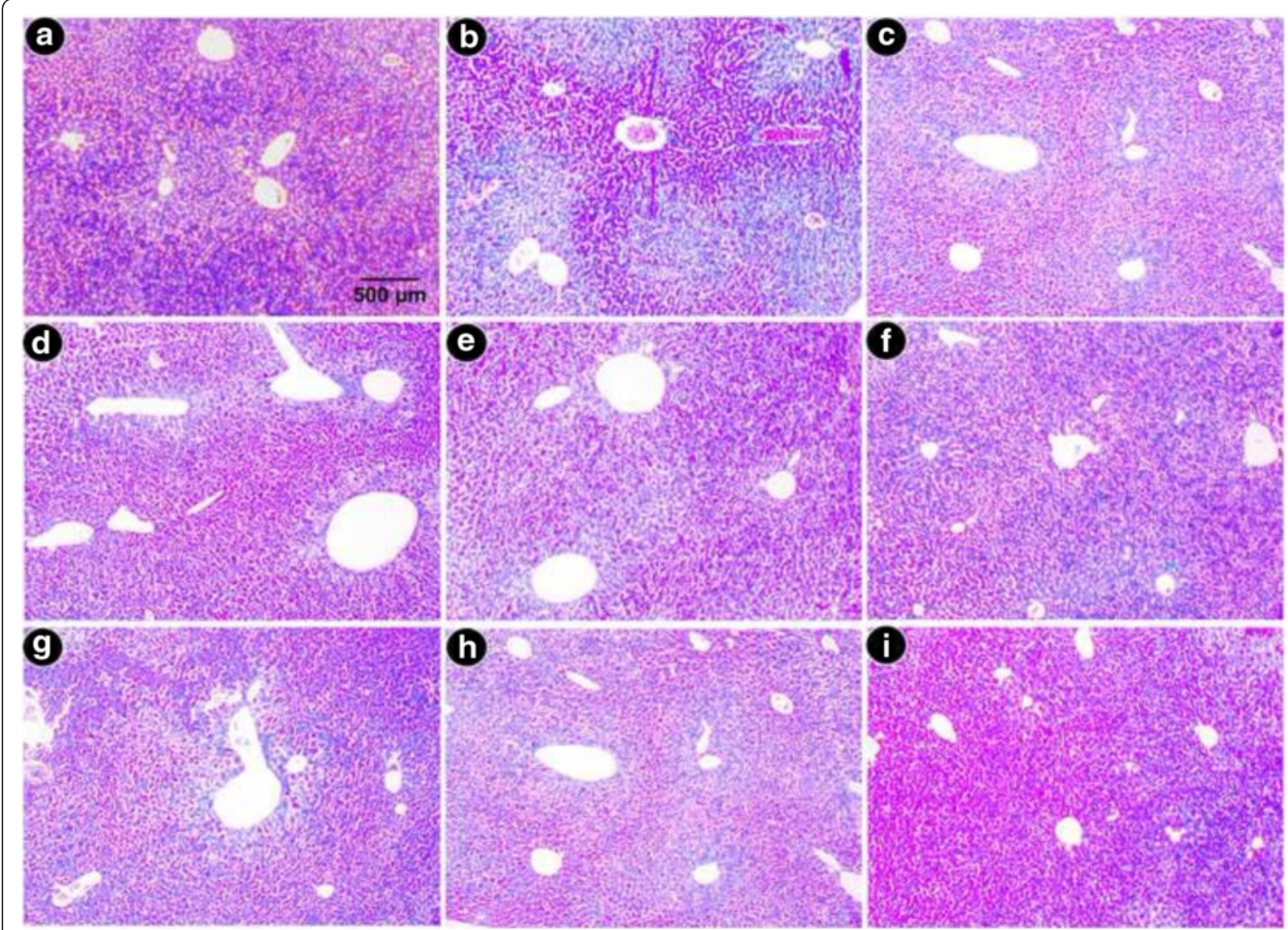

Fig. 10 Microscopic observation of liver sections stained with Masson's Trichrome $\times 100$. a Liver sections from control mice displayed normal cellular integrity with no fibrosis. b Liver sections from iron-overloaded mice displayed elongated fibrous septa and collagen accumulation (blue). c Desirox-treated liver section $\mathbf{d}$. Liver section from the R2 mouse group with lesser blue patches. e Liver section from the R4 mouse group (f). Liver section from the R8 mouse group (g). Liver section from the S2 mouse group (h). Liver section from the S4 mouse group (i). Liver section from the 58 mouse group. MG demonstrates a nearly negligible collagen accumulation and healthy liver. Higher doses of both GA and MG demonstrate reduced collagen deposition, fibrous septum and necrotic cells in periportal veins, indicating a trend of restoration of normal cellular integrity

alcohol-induced liver injury and chronic hepatitis C [46]. Subsequent to hepatic cellular damage, collagen production predominates over hepatocellular regeneration as an immediate healing response, thereby occupying the injured areas instead of destroyed hepatocytes. Collagen content is therefore considered to be a major marker of liver fibrosis and hepatotoxicity [47]. Iron-induced liver pathogenicity also leads to the oxidation of various important structural and functional proteins and forms protein carbonyls. Thus, it serves as a marker of oxidative stress and leads to the onset/development of various diseases including cystic fibrosis and ulcerative colitis [30]. The chelation of excess iron by MG and GA further strengthen the position of GA and MG in significantly overcoming hepatic damage/fibrosis in iron intoxicated mice, indicating the hepato-ameliorating potency of the compounds.
A liver biopsy is considered to be the gold-standard method for assessment of the degree of inflammation and fibrosis alongside other biochemical tests. The liver sections stained with hematoxylin and eosin exhibited various degrees of inflammation, necrosis as well as cell wall degeneration in iron overloaded condition, but dose dependent treatment reduced the tissue damage that also supported the result of the restoration of serum enzyme and antioxidant enzyme levels. Perls' Prussian blue staining revealed the visual confirmation of iron chelation property of the test compounds along with the liver iron content and serum ferritin content. On the other hand, Masson's trichrome staining disclosed the reduction of liver fibrosis as the collagen content gradually decreased with the increasing doses of GA and MG, which also confirmed the anti-fibrotic effect of the fraction along with the test for collagen content. Overall 
results in histopathological studies signifying in situ evidence of ameliorating the effect of the iron overloadinduced liver toxicity.

\section{Conclusion}

Excess iron plays a critical role in oxidative stress-related hepato-toxicity and liver fibrosis, which is profoundly supported by the results of the present study. Among the isolated compounds from S. pinnata bark, MG exhibited exceptional amelioration potential for hepatotoxicity mainly due to its iron chelation capacity. In contrast, GA failed to demonstrate brilliant iron chelation activity in vitro, but it displayed a pleasing amendment of oxidative stress and liver damage as it neutralized excess generated free radicals due to iron overload before they could attack any bio-entities. Thus, these two compounds act in different pathways to achieve the same goal. Although the isolated compounds showed similar effect as desirox, they proved the rationale behind the activity of the S. pinnata bark extract, which was already proven as better and safer drug than standard Desirox. These findings also suggest the beneficiary role of GA and MG in the pathological sequence of iron-overload-linked liver disease and fibrosis.

\section{Additional file}

Additional file 1: Spectroscopic data of SPE3 and SPE4. (DOCX 9715 kb)

\begin{abstract}
Abbreviations
ALAT, alanine aminotransferase; ALP, alkaline phosphatase; ANOVA, analysis of variance; ASAT, aspartate aminotransferase; b.w., body weight; BSA, bovine serum albumin; CAT, catalase; CDNB, 1-chloro-2,4-dinitrobenzene; CNCl, Chittaranjan National Cancer Institute; CPCSEA, Committee for the Purpose of Control and Supervision of Experiments on Animals; CRIA, Central Research Institute of Ayurveda; DCFDA, 2,7-dichlorofluorescein diacetate; DTNB, 5,5'-dithiobis-2nitrobenzoic acid; EDTA, ethylenediamine tetraacetic acid; EIMS, electron ionization mass spectrometry; ELISA, enzyme-linked immunosorbent assay; FITC, fluorescein isothiocyanate; FT-IR, fourier transform infrared spectroscopy; 9 , gram; GA, gallic acid; GSH, reduced glutathione; GST, glutathione-S-transferase; HPLC, high performance liquid chromatography; i.p, intraperitoneal; kg, kilogram; M, molar; MDA, malondialdehyde; $M G$, methyl gallate; mg, milligram; $\mathrm{ml}$, milliliter; mM, Millimolar; NED, N-(1-Naphthyl) ethylenediamine dihydrochloride; NMR, nuclear magnetic resonance; PBS, phosphate buffer saline; RNS, reactive nitrogen species; ROS, reactive oxygen species; SD, standard deviation; SOD, superoxide dismutase; TBARS, thiobarbituric acid reactive substances
\end{abstract}

\section{Acknowledgments}

The authors would like to acknowledge Mr. Ranjit K. Das and Mr. Pradip K. Mallick for their technical assistance.

\section{Funding}

This study was conducted with the financial support from Council of Scientific and Industrial Research (CSIR), Govt. of India [Grant No: 27(210)/09-EMR-II Dated: 15.10.2009].

\section{Availability of data and materials}

The datasets supporting the conclusions of this article are included within the article.

\section{Authors' contributions}

Conceived and designed the experiments: NM. Performed the experiments: DC, NBG, SP. Analyzed the data: DC. Contributed reagents/materials/analysis tools: NM. Wrote the paper: DC, NBG, NM. It is also confirm that all the authors have read and approve of the manuscript.

\section{Competing interests}

The authors declare that they have no competing interests.

\section{Consent for publication}

The manuscript does not contain any individual person's data in any form. So, this information is not relevant.

\section{Ethics approval and consent to participate}

Manuscripts dose not deals with the human participants, human data or human tissue. So, this information is not relevant.

In vivo experiments were performed abiding by the guidelines of the Committee for the Purpose of Control and Supervision of Experiments on Animals (CPCSEA), Ministry of Environment and Forest, Govt. of India with due approval from the Institutional Animal Ethics Committee, Bose Institute (Registration. No. 95/1999/CPCSEA).

Received: 10 March 2016 Accepted: 14 July 2016

Published online: 26 July 2016

\section{References}

1. Braca A, Sortino C, Politi M, Morelli I, Mendez J. Antioxidant activity of flavonoids from Licania licaniaeflora. J Ethnopharmacol. 2002;79:379-81.

2. Ercal N, Gurer-Orhan H, Aykin-Burns N. Toxic metals and oxidative stress part I: mechanisms involved in metal-induced oxidative damage. Curr Top Med Chem. 2001;1:529-39.

3. Ha HL, Shin HJ, Feitelson MA, Yu DY. Oxidative stress and antioxidants in hepatic pathogenesis. World J Gastroenterol. 2010;16:6035-43.

4. Ramm GA, Ruddell RG. Hepatotoxicity of iron overload: mechanisms of iron-induced hepatic fibrogenesis. Semin Liver Dis. 2005;25:433-49.

5. Flora SJ. Structural, chemical and biological aspects of antioxidants for strategies against metal and metalloid exposure. Oxid Med Cell Longev. 2009;2:191-206.

6. Pardo-Andreu GL, Barrios MF, Curti C, Hernandez I, Merino N, Lemus Y, et al. Protective effects of Mangifera indica $L$ extract (Vimang), and its major component mangiferin, on iron-induced oxidative damage to rat serum and liver. Pharmacol Res. 2008;57:79-86.

7. Hazra B, Biswas S, Mandal N. Antioxidant and free radical scavenging activity of Spondias pinnata. BMC Complement Altern Med. 2008:8:63.

8. Hazra B, Sarkar R, Mandal N. Spondias pinnata stem bark extract lessens iron overloaded liver toxicity due to hemosiderosis in Swiss albino mice. Ann Hepatol. 2013;12:123-9.

9. Chaudhuri D, Ghate NB, Singh SS, Mandal N. Methyl gallate isolated from Spondias pinnata exhibits anticancer activity against human glioblastoma by induction of apoptosis and sustained extracellular signal-regulated kinase 1/2 activation. Pharmacogn Mag. 2015;11:269-76.

10. Ghate NB, Chaudhuri D, Mandal N. In vitro antioxidant and free radical scavenging assessment of Tinospora cordifolia stem with DNA protective potential. Int J Pharm Bio Sci. 2013;4:373-88.

11. Lowry $\mathrm{OH}$, Roesborough MJ, Farr AL, Randall RJ. Protein measurement with Folin-Phenol reagent. J Biol Chem. 1951;193:265-75.

12. Barry M, Sherlock S. Measurement of liver iron concentration in needle-biopsy specimens. Lancet. 1971;297:100-3.

13. Hynes MJ, Coinceanainn M. Investigation of the release of iron from ferritin by naturally occurring antioxidants. J Inorg Biochem. 2002;90:18-21.

14. Kakkar P, Das B, Viswanathan PN. A modified spectrophotometric assay of superoxide dismutase. Indian J Biochem Biophys. 1984;21:130-2.

15. Bonaventura J, Schroeder WA, Fang S. Human erythrocyte catalase: an improved method of isolation and a re-evaluation of reported properties. Arch Biochem Biophys. 1972;150:606-17.

16. Habig WH, Pabst MJ, Jakoby WB. Glutathione-S-transferases. The first enzymatic step in mercapturic acid formation. J Biol Chem. 1974;249:7130-9.

17. Ellman GL. Tissue sulfhydryl group. Arch Biochem Biophys. 1959;82:70-7.

18. Rashid K, Bhattacharya S, Sil PC. Protective role of D-saccharic acid-1,4lactone in alloxan induced oxidative stress in the spleen tissue of diabetic 
rats is mediated by suppressing mitochondria dependent apoptotic pathway. Free Radic Res. 2012;46:240-52.

19. Buege JA, Aust SD. Microsomal lipid peroxidation. Methods Enzymol. 1978;52:302-10

20. Reznick AZ, Packer L. Oxidative damage to proteins: spectrophotometric method for carbonyl assay. Methods Enzymol. 1994:233:357-3.

21. Bergman I, Loxley R. Two improved and simplified methods for the spectrophotometric determination of hydroxyproline. Anal Chem. 1963; 35:1961-5.

22. Kivirikko Kl, Laitinen O, Prockop DJ. Modifications of a specific assay for hydroxyproline in urine. Anal Biochem. 1967;19:249-55.

23. Halliwell B, Aruoma OI. DNA damage by oxygen-derived species. Its mechanism and measurement in mammalian systems. FEBS Lett. 1991; 281:9-19.

24. Bonkovsky HL. Iron and the liver. Am J Med Sci. 1991;301:32-43.

25. Rothman RJ, Serroni A, Farber JL. Cellular pool of transient ferric iron, chelatable by deferoxamine and distinct from ferritin, that is involved in oxidative cell injury. Mol Pharmacol. 1992;42:703-10.

26. Sarkar R, Hazra B, Mandal N. Reducing power and iron chelating property of Terminalia chebula (Retz.) alleviates iron induced liver toxicity in mice. BMC Complement Altern Med. 2012;12:144.

27. Hazra B, Sarkar R, Mandal N. Protection of Terminalia belerica Roxb. against iron overload induced liver toxicity: an account of its reducing and iron chelating capacity. American J Pharmacol Toxicol. 2012;7: 109-22.

28. Yang S, Bai G, Chen L, Shen Q, Diao X, Zhao GS. The interaction of phenolic acids with $\mathrm{Fe}$ (III) in the presence of citrate as studied by isothermal titration calorimetry. Food Chem. 2014;157:302-9.

29. Galleano M, Simontacchi M, Puntarulo S. Nitric oxide and iron: effect of iron overload on nitric oxide production in endotoxemia. Mol Aspect Med. 2004; 25:141-54.

30. Zuyderhoudt FM, Sindram JW, Marx JJ, Jörning GG, Van Gool J. The amount of ferritin and hemosiderin in the livers of patients with iron-loading diseases. Hepatology. 1983;3:232-5.

31. Harrison PM. Ferritin: an iron-storage molecule. Semin Hematol. 1977;14:55-70.

32. O'Brien RT. Ascorbic acid enhancement of desferrioxamine induced urinary iron excretion in thalassemia major. Ann N Y Acad Sci. 1974;232: 221-5.

33. Sabir SM, Ahmad SD, Hamid A, Khand MQ, Athaydeb ML, Santosa DB, et al. Antioxidant and hepatoprotective activity of ethanolic extract of leaves of Solidago microglossa containing polyphenolic compounds. Food Chem. 2012;131:741-7.

34. Lledias F, Rangel P, Hansberg W. Oxidation of catalase by singlet oxygen. J Biol Chem. 1998:273:10630.

35. Eruslanov E, Kusmartsev S. Identification of ROS using oxidized DCFDA and flow-cytometry. Methods Mol Biol. 2010;594:57-72.

36. Zhang A, Fang Y, Wang H, Li H, Zhang Z. Free-radical scavenging properties and reducing power of grape cane extracts from 11 selected grape cultivars widely grown in China. Molecules. 2011;16:10104-22.

37. Roche M, Rondeau P, Singh NR, Tarnus E, Bourdon E. The antioxidant properties of serum albumin. FEBS Lett. 2008;582:1783-7.

38. Liu T, Wang X, Karsdal MA, Leeming DJ, Genovese F. Molecular serum markers of liver fibrosis. Biomark Insights. 2012;7:105-17.

39. Khatri A, Garg A, Agrawal SS. Evaluation of hepatoprotective activity of aerial parts of Tephrosia purpurea L. and stem bark of Tecomella undulate. J Ethnopharmacol. 2009;122:1-5.

40. Pulla Reddy A, Lokesh BR. Effect of curcumin and eugenol on iron-induced hepatic toxicities in rats. Toxicol. 1996;107:39-45.

41. Thabrew M, Joice P. A comparative study of the efficacy of Pavetta indica and Osbeckia octanda in the treatment of liver dysfunction. Planta Med. 1987;53:239-41.

42. Ryan TP, Aust SD. The role of iron in oxygen-mediated toxicities. Crit Rev Toxicol. 1992;22:119-41.

43. Lee KS, Buck M, Houglum K, Chojkier M. Activation of hepatic stellate cells by TGF alpha and collagen type I is mediated by oxidative stress through c-myb expression. J Clin Invest. 1995;96:2461-8.

44. Farinati F, Cardin R, De Maria N, Della Libera G, Marafin C, Lecis E, et al. Iron storage, lipid peroxidation and glutathione turnover in chronic anti HCV positive hepatitis. J Hepatol. 1995;22:449-56.
45. Reeves HL, Burt AD, Wood S, Day CP. Hepatic stellate cell activation occurs in the absence of hepatitis in alcoholic liver disease and correlates with the severity of steatosis. J Hepatol. 1996;25:677-83.

46. Plebani M, Burlina A. Biochemical markers of hepatic fibrosis. Clin Biochem. 1991;24:219-39.

47. Dalle-Donne I, Rossi R, Giustarini D, Milzani A, Colombo R. Protein carbonyl groups as a biomarkers of oxidative stress. Clin Chim Acta. 2003;329:23-8.

\section{Submit your next manuscript to BioMed Central and we will help you at every step:}

- We accept pre-submission inquiries

- Our selector tool helps you to find the most relevant journal

- We provide round the clock customer support

- Convenient online submission

- Thorough peer review

- Inclusion in PubMed and all major indexing services

- Maximum visibility for your research

Submit your manuscript at www.biomedcentral.com/submit
C Biomed Central 